\title{
Effect of myocardial protection and perfusion temperature on production of cytokines and nitric oxide during cardiopulmonary bypass $^{1}$
}

\author{
Efeito da proteção miocárdica e temperatura de perfusão sobre a produção de \\ citocinas e óxido nítrico durante bypass cardiopulmonar
}

\author{
Beatriz Martins Tavares-Murta ${ }^{2}$, Adriana Oliveira Cordeiro ${ }^{3}$, Eddie Fernando Candido Murta ${ }^{4}$, Fernando de \\ Queiroz Cunha5 ${ }^{5}$ Flora Margarida Barra Bisinotto ${ }^{6}$ \\ 1. Research performed at Department Biological Sciences and Surgical Clinic, Federal University of Triângulo Mineiro (UFTM) and Department of \\ Pharmacology, Faculty of Medicine of Ribeirão Preto, University of São Paulo (USP), Brazil. \\ 2. MD, PhD, Assistant Professor, Department of Biological Sciences, UFTM, Uberaba - Minas Gerais (MG), Brazil. \\ 3. Resident of Anaesthesiology, Department of Surgical Clinic, UFTM, Uberaba (MG), Brazil. \\ 4. MD, PhD, Full Professor, Research Institute of Oncology (IPON), UFTM, Uberaba (MG), Brazil. \\ 5. PhD, Full Professor, Department of Pharmacology, Faculty of Medicine of Ribeirão Preto, USP, Ribeirão Preto - São Paulo (SP), Brazil. \\ 6. MD, PhD, Assistant Professor, Department of Surgical Clinic, UFTM, Uberaba (MG), Brazil.
}

\begin{abstract}
Purpose: To investigate the effects of different conditions used during cardiopulmonary bypass (CPB) surgery on accompanying production of cytokine and nitric oxide (NO). Methods: Patients undergoing CPB for the first time were prospectively enrolled and divided into two groups according to CPB parameters performed: i) normothermia (36.5$37^{\circ} \mathrm{C}$ ) with blood cardioplegia (NB group, $\mathrm{n}=10$ ) and ii) hypothermia $\left(29-31^{\circ} \mathrm{C}\right.$ ) with crystalloid cardioplegia (HC group, $\mathrm{n}=10$ ). Plasma samples obtained following intubation (baseline), during ( 5 and $30 \mathrm{~min}$ ) and after ( 4 and $24 \mathrm{~h}$ ) CPB were assayed for cytokines (ELISA) and NO metabolites (Griess reaction). Results: Peak concentrations of interleukin (IL)6 and IL-8 were reached at $4 \mathrm{~h}$ post CPB in both groups, but in the HC group those levels increased earlier and persisted for longer $(24 \mathrm{~h})$ compared to baseline $(P<0.05)$. IL-10 levels also increased at $4 \mathrm{~h}$ compared to baseline, but only significantly so in the HC group. NO metabolites were reduced in HC group at all time points compared to baseline $(P<$ 0.05), while no significant differences were detected in the NB group. Conclusion: The association between increased systemic levels of cytokines and reduced NO production in the HC group suggests that different myocardial protection and/or perfusion temperature used during CPB may contribute to the extent of inflammatory response.
\end{abstract}

Key words: Cardiopulmonary Bypass. Myocardium. Perfusion. Nitric Oxide. Cytokines.

\section{RESUMO}

Objetivo: Investigar a hipótese de que diferentes procedimentos durante o bypass cardiopulmonary (BCP) causa diferentes níveis de citocinas (IL) e óxido nítrico (NO). Métodos: Pacientes submetidas a BCP foram prospectivamente estudadas de acordo com bypass realizado sobre normotermia $\left(36.5-37^{\circ} \mathrm{C}\right)$ com cardioplegia sanguínea (NB group, $\left.\mathrm{n}=10\right)$ or hipotermia $\left(29-31^{\circ} \mathrm{C}\right.$ ) com cardioplegia cristalóide (HC group, n=10). Amostras de Plasma foram obtidas após a intubação (linha de base), durante (5, 30 min) e após (4, 24 h) o BCP. Os ensaios foram realizados através de ELISA (IL) e metabólitos do NO (reação de Griess). Resultados: Os picos de concentrações de IL-6 and IL-8 estavam aumentados em 4 h pós BCP em ambos os grupos, mas no grupo HC estes níveis aumentaram precocemente e persistiram aumentadas por $24 \mathrm{~h}$, comparado a linha de base $(P<0.05)$. O nível de IL-10 também teve o pico em 4 h, mas estatisticamente significante somente no grupo HC, comparado a linha de base. Os metabólitos do NO estavam reduzidos no grupo HC, em todo o tempo, comparado a linha de base $(P<0.05)$, enquanto nenhuma diferença estatisticamente significante foi detectada no grupo NB. Conclusão: A associação entre o aumento sistêmico dos níveis de citocina e a redução da produção de NO no grupo HC sugere que o tipo de proteção miocárdica e/ou temperatura de perfusão no BCP pode ser um fator determinante na extensão da resposta inflamatória.

Descritores: Ponte Cardiopulmonar. Miocárdio. Perfusão. Óxido Nítrico. Citocinas. 


\section{Introduction}

Cardiac surgery with cardiopulmonary bypass (CPB) can induce systemic inflammatory response syndrome (SIRS), which is characterized by fever, increased respiratory and heart rate (or a $\mathrm{PaCO}_{2}$ level of less than $32 \mathrm{mmHg}$ ), and an abnormal white blood cell count. The underlying causes of SIRS include surgical trauma, blood exposure to foreign surfaces, ischemia/ reperfusion injury, mechanical shear stress, hemodilution, release of endotoxin and perfusion temperature $^{1}$. Several inflammatory pathways are activated following $\mathrm{CPB}$, including the complement system, the coagulation cascade in blood, inflammatory responses in endothelial cells, and circulating leukocyte adhesion processes. Although the inflammatory process is self-limiting in most patients, excessive inflammation may be associated with morbidity and mortality caused by organ dysfunction ${ }^{1}$. The clinical manifestation of SIRS following CPB is mediated via cell-derived cytokines that target end-organ receptors. After CPB, elevated serum levels of the pro-inflammatory cytokines, tumor necrosis factor (TNF)-a, interleukin (IL)-6 and IL-8, as well as the anti-inflammatory cytokine IL-10 have been found ${ }^{2,3}$. The potent vasodilator nitric oxide (NO) has also been implicated in SIRS pathophysiology. NO production is catalyzed by inducible NO synthase (iNOS). The inability to produce sufficient NO during early reperfusion in $\mathrm{CPB}$ that is caused by temporary endothelial cell dysfunction may be related to vasospasm that occurs with ischemia and reperfusion ${ }^{4}$. The CPB procedure can be performed under normothermic or hypothermic conditions, and these perfusion temperatures do not appear to affect the degree of inflammatory response or hemodynamics produced ${ }^{5,6}$. However, more recently, it was reported that correcting perioperative hypothermia decreases mortality in experimental sepsis which is associated with reduced IL6 levels $^{7}$. In contrast, animals submitted to CPB under moderate hypothermia had lower histological organ damage scores compared to those treated under normothermia. The reduced organ damage at a lower body temperature was associated with reduced plasma levels of TNF-a ${ }^{8}$. In addition to perfusion temperature during $C P B$, cardioplegia type may influence the production of inflammatory mediators, since the myocardium is an important source of cytokines ${ }^{9,10}$. In the present study we examined the effects of different myocardial protection conditions and perfusion temperatures on the systemic inflammatory response following CPB cardiac surgery. To do this, we assessed systemic levels of pro- and anti-inflammatory cytokines and NO in patients receiving CPB performed by two different procedures: (1) normothermia with blood cardioplegia, or (2) hypothermia with crystalloid cardioplegia.

\section{Methods}

\section{Subjects}

This study was approved by UFTM ethics committee. After giving informed consent, 20 patients undergoing elective coronary artery grafting or valve operation were prospectively enrolled. Patients were randomly divided into two groups: one that received hypothermic bypass with crystalloid cardioplegia (HC group, $n=10$ ) or normothermic bypass with blood cardioplegia (NB group, $n=10$ ). Of the ten patients in each group, 9 received revascularization and one a valve change. For all patients, the following general data were collected: age, sex, weight, height and body mass. Exclusion criteria were patients with severely impaired left ventricular function (ejection fraction $<40 \%$ ), previous cardiac procedures, severe systemic noncardiac disease, recent myocardial infarction ( $<6 \mathrm{wks}$ ), infectious disease before operation, or impaired lung, liver or renal function.

\section{Anesthesia and surgical techniques}

Anesthetic techniques were standardized for all patients; they received midazolam $15 \mathrm{mg}$ orally $1 \mathrm{~h}$ before operation. Central venous and radial artery cannulas were inserted under local anesthesia (1\% lignocaine) and midazolam sedation (5.0 $\mathrm{mg}$ intravenously). Anesthesia was induced with sufentanyl $(0.5 \mathrm{mg} / \mathrm{kg})$ and etomidate $(0.3 \mathrm{mg} / \mathrm{kg})$; succinylcoline $(1.5 \mathrm{mg} / \mathrm{kg})$ was used for neuromuscular blockade. Lungs were ventilated with oxygen $(1 \mathrm{~L} / \mathrm{min})$ containing isoflurane (0.5 to $1.5 \%)$, to maintain anesthesia, and sufentanyl (0.5-1.0 mg/kg/h) and pancuronium bromide $(0.1 \mathrm{mg} / \mathrm{kg})$. During CPB, patients received continuous infusion of propofol $(4.0 \mathrm{mg} / \mathrm{kg} / \mathrm{h})$ and sufentanyl (0.5$1.0 \mathrm{mg} / \mathrm{kg} / \mathrm{h})$. Patients were ventilated with a tidal volume of $6.0-8.0 \mathrm{ml} / \mathrm{kg}$, aiming at normocapnia. Perioperative antibiotic prophylaxis consisted of cefazolin ( 2 g every $4 \mathrm{~h}$ during the procedure and every $6 \mathrm{~h}$ for $24 \mathrm{~h}$ thereafter). The extracorporeal circuit consisted of a roller pump, a cardiotomy reservoir, and a membrane oxygenator. The circuit was primed with $1500 \mathrm{ml}$ of Ringer's lactate solution, sodium bicarbonate and mannitol 15\% (2 ml/kg). CPB was established using ascending aortic cannulation and two-stage venous cannulation in the right atrium. Intravenous heparin was administered to achieve an activated clotting time of $>480$ s. After the start of CPB, patients in the $\mathrm{HC}$ group were cooled to 29 to $31^{\circ} \mathrm{C}$, whereas patients from NB group were maintained at 36.5 to $37^{\circ} \mathrm{C}$. Flow rates of $2.4 \mathrm{~L} / \mathrm{m}^{2} /$ min were used. The management of myocardial protection differed between the groups, as follows: in the HC group, myocardial protection was achieved by inducing electromechanical arrest with cold, anterograde 
crytalloid cardioplegia using St. Thomas’s I solution and topical cooling using normal saline solution $\left(4^{\circ} \mathrm{C}\right)$. One liter of cardioplegia was administered initially followed by $300 \mathrm{ml}$ every $30 \mathrm{~min}$ of cross-clamping or earlier, whenever electrical activity was seen. In the NB group, cardiac arrest was achieved by using intermittent anterograde hyperkalemic warm blood cardioplegia. At the end of bypass, anti-coagulation was reversed with protamine sulfate in both groups. After the surgery was completed, patients were transferred to an Intensive Care Unit, where standard care was followed until discharge. Extubation was performed as soon as patients were able to maintain adequate gas exchange with normal blood gases during spontaneous breathing, when they were haemodynamically stable and had satisfactory renal function.

\section{Intraoperative measurements and plasma samples}

Intraoperative variables included operation and bypass time, aortic cross-clamp time and duration of intubation. Serial blood samples $(10 \mathrm{ml})$ were withdrawn from the radial artery catheter 5 min after intubation (baseline), 5 and 60 min after the beginning of CPB, and 4 and $24 \mathrm{~h}$ after the end of CPB. The samples were collected in EDTA-containing tubes and centrifuged at $3000 \mathrm{X}$ g for $15 \mathrm{~min}$. Plasma was collected and stored ($70^{\circ} \mathrm{C}$ ) until assays for cytokines and NO were performed.

\section{Cytokine measurements}

The concentrations of IL-6, IL-8 and IL-10 in plasma samples were determined by ELISA. Briefly, flatbottomed 96-well microtiter plates were coated with specific antibody (100 $\mu \mathrm{l} /$ well) diluted in coating buffer ( $1 \mu \mathrm{g} / \mathrm{ml}$ for IL-6 and IL-8 or $3 \mu \mathrm{g} / \mathrm{ml}$ for IL-10; PharMingen, San Diego, CA) and incubated overnight at $4^{\circ} \mathrm{C}$. The plates were then washed and non-specific binding was blocked $\left(120 \mathrm{~min}, 37^{\circ} \mathrm{C}\right)$ with $1 \%$ bovine serum. Non-diluted samples and standards were loaded onto plates. Recombinant human IL-6, IL-8 and IL-10 (PharMingen, San Diego, CA) standard curves were used to calculate the cytokine concentrations. The plates were thoroughly washed and the appropriate biotinylated polyclonal or monoclonal anti-cytokine antibody was added. The plates were washed $1 \mathrm{~h}$ later; then avidin peroxidase (diluted 1:5000) was added to each well for $15 \mathrm{~min}$ and each plate was thoroughly washed again. Substrate $(0.4 \mathrm{mg}$ of o-phenylenediamine dihydrochloride [Sigma, St. Louis, MO] $+0.4 \mu \mathrm{l}$ of hydrogen peroxide [Merck, Rio de Janeiro, RJ, Brazil] per $1 \mathrm{ml}$ of substrate buffer) was added and the reaction was stopped with $\mathrm{H}_{2} \mathrm{SO}_{4}(1 \mathrm{M})$. The optical density was measured on a plate reader (Spectra Max 250 - Molecular device, Sunnyvale, CA) at $490 \mathrm{~nm}$. The optical density in the samples was compared with standard curves and results were expressed as picograms of each cytokine per $1 \mathrm{ml}$ of plasma.

\section{Determination of NO metabolites}

The nitrite $\left(\mathrm{NO}_{2}\right)$ plus nitrate $\left(\mathrm{NO}_{3}\right)$ concentration in samples was determined by enzymatically reducing nitrate with nitrate reductase. Briefly, non-diluted plasma samples $(50 \mathrm{ml})$ were incubated with the same volume of reductase buffer (0.1 M potassium phosphate, $\mathrm{pH} 7.5$, containing $1 \mathrm{mM}$ NADPH, $10 \mathrm{mM}$ FAD and $4 \mathrm{U}$ of nitrate reductase $\mathrm{ml}^{-1}$ ) for $20 \mathrm{~h}$ at $37^{\circ} \mathrm{C}$. A standard nitrate curve was obtained by incubating sodium nitrate (10 to $200 \mathrm{mM}$ ) with the reductase buffer. The total amount of nitrite was then determined by the colorimetric Griess method. Briefly, samples were incubated with the same volume of freshly prepared Griess reagent (1\% sulphanilamide, $0.1 \%$ naphthylethylenediamine dihydrochloride in 5\% phosphoric acid). Absorbance at $550 \mathrm{~nm}$ was determined using a multi-well plate reader (Multiskan MCC/340 MKII, Flow Laboratories). The results are reported as micromoles $(\mathrm{mM})$ of $\mathrm{NO}_{3}+\mathrm{NO}_{2}$.

\section{Statistical analysis}

Data were analyzed with SigmaStat software. General characteristics or time points were compared between groups using the Mann-Whitney test. Repeated measures analysis of variance for paired data (Friedman's test) was used to assess changes over time in each group. If significance was found, Dunnett's post-doc test was used for comparisons with the basal time point. Correlations between peak levels of cytokines and NO in each group were assessed by Spearman's rank correlation. In all cases $P<0.05$ was considered statistically significant.

\section{Results \\ Study population}

Clinical characteristics of the study groups are summarized in Table 1. Subjects in the two groups did not differ significantly in age, sex, total operation time, bypass time, cross-clamp time or intubation time. The groups also did not differ in weight, height or body mass (data not shown). One patient (representing 10\% of the population) from the HC group died. 
TABLE 1 - General and intraoperative characteristics of patient groups subjected to CPB surgery under different myocardial protection conditions and perfusion temperatures

\begin{tabular}{lll}
\hline & NB group & HC group \\
\hline Sex (M/F) & $6 / 4$ & $9 / 1$ \\
Age (yrs) & $58.5(54-80)$ & $61(26-72)$ \\
Operation time (min) & $255(155-465)$ & $305(170-450)$ \\
Bypass time (min) & $95(60-115)$ & $81(55-90)$ \\
Cross-clamp time (min) & $65(37-90)$ & $43.5(29-80)$ \\
Intubation time (h) & $11.5(5-18.2)$ & $17.9(4.1-72)$ \\
\hline
\end{tabular}

NB: normothermia with blood cardioplegia, HC: hypothermia with crystalloid cardioplegia. Values are medians and range in parentheses; $n=10$ per group.

\section{Cytokine assay}

The systemic production of IL-6, IL-8 and IL-10 was evaluated at different time points during (5 and 30 min, T1 and T2) and after (4 and 24 h, T3 and T4) bypass and compared to baseline levels (T0). The basal concentrations of the cytokines were below the limit of detection in most patients for IL-6 (Figure 1) and IL-10 (Figure 3), but were detected in $80 \%$ patients from both groups for IL-8 (Figure 2). Thus, basal systemic levels of IL-6 and IL-10 were below the limit of sensitivity in our assay, since low levels are not likely attributable to a problem with the assay because the cytokines were detected in some patient samples, as observed by maximum values, and in the control curve. In both the HC and NB groups, plasma IL-6 (Figure 1) and IL-8 (Figure 2) reached peak concentrations $4 \mathrm{~h}$ after the end of bypass. In the NB group, IL-6 and IL-8 levels were significantly elevated only at $4 \mathrm{~h}$ compared to baseline, and then returned to control values at $24 \mathrm{~h}$ later (Figures 1 and 2, panel A, respectively). In the $\mathrm{HC}$ group, significantly increased cytokine levels were detected at 5 and 30 min after the beginning of bypass compared to baseline, and, for IL-6 and IL-8, persisted for $24 \mathrm{~h}$ thereafter (Figures 1 and 2, panel B, respectively). Furthermore, peak levels of IL-6 were significantly higher in HC than NB groups, and a significant correlation $(p<0.01)$ was found between peak levels of IL-6 and IL-8. Regarding IL-10, although plasma levels peaked at $4 \mathrm{~h}$ in both groups, statistical significance was detected only for HC group compared to baseline (Figure 3).

\section{Plasma nitrate concentration}

Plasma samples, obtained at the same time as blood collection for the cytokine assay, were also tested for $\mathrm{NO}_{3}+\mathrm{NO}_{2}$ levels. In NB group these concentrations were not altered compared to baseline, but in $\mathrm{HC}$ group, NO metabolites were significantly reduced at all time points evaluated compared to the basal median value (Figure 4).

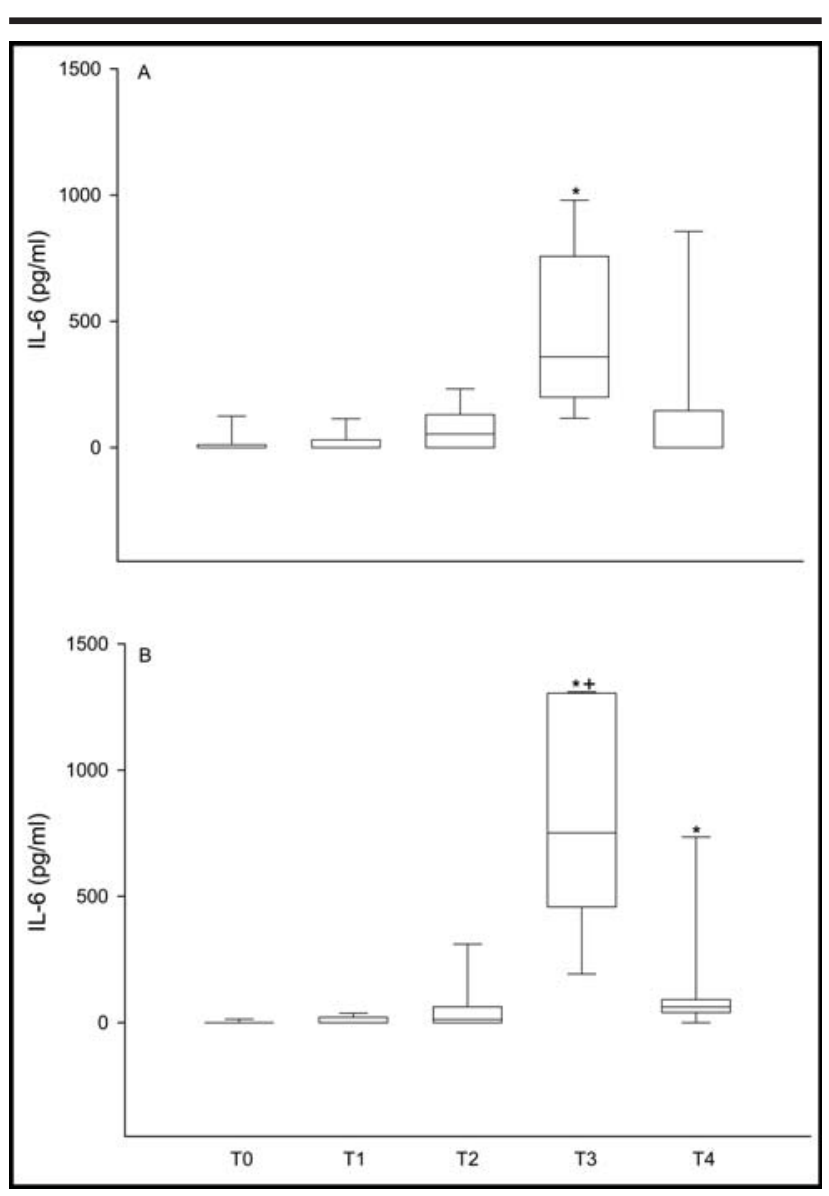

FIGURE 1 - Plasma IL-6 concentrations during and after bypass. Patients were submitted to bypass under normothermia with blood cardioplegia $(n=10$, panel A) or hypothermia with crystalloid cardioplegia ( $\mathrm{n}=10$, panel $\mathrm{B}$ ). Time points for the assay were: baseline (after intubation, T0), 5 and 30 min after bypass start (T1 and T2), and 4 and 24 h after the end of bypass (T3 and T4). The $25^{\text {th }}$ and $75^{\text {th }}$ percentiles are represented by a bar centered about the median; ranges are depicted by the error bars. ${ }^{*} P<0.05$ compared to baseline (Friedman test followed by Dunnett), $\uparrow P<$ 0.05 compared to the same time point from NB group in panel A (Mann-Whitney) 


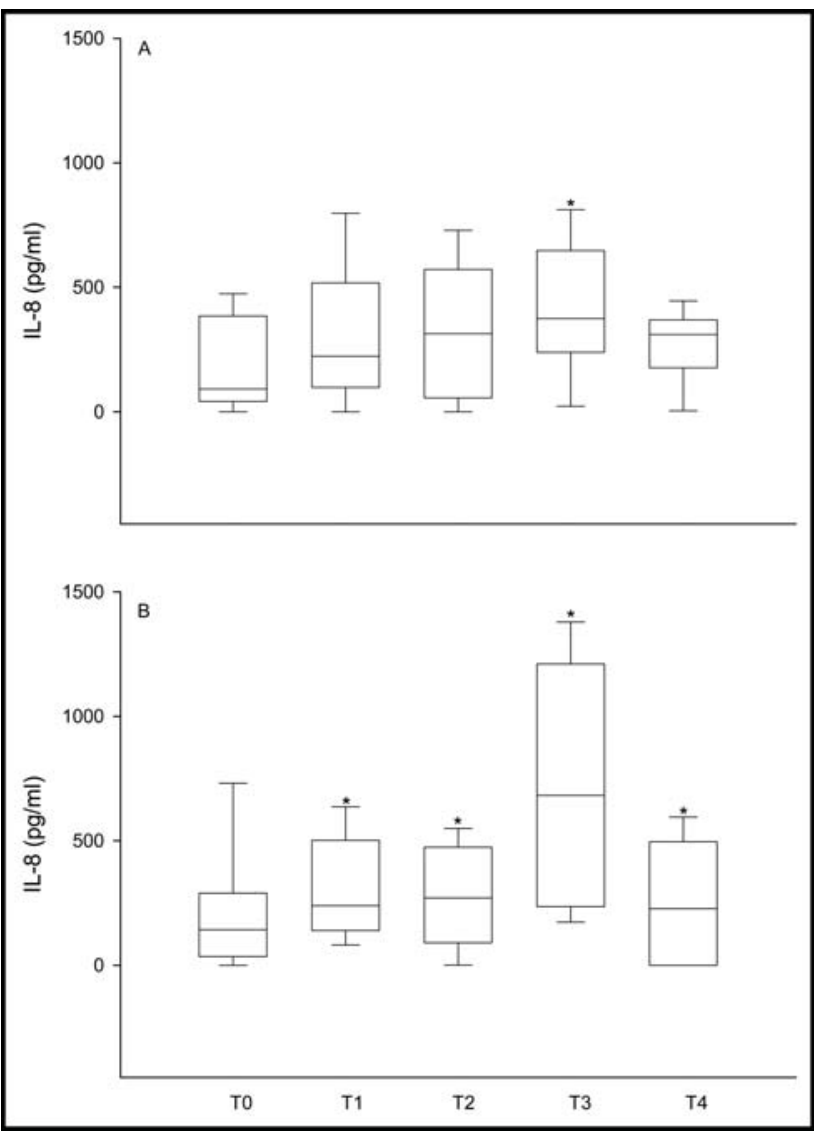

FIGURE 2 - Plasma IL-8 concentrations during and after bypass. Patients were submitted to bypass under normothermia with blood cardioplegia $(n=10$, panel A) or hypothermia with crystalloid cardioplegia ( $n=10$, panel B). Time points for the assay were: baseline (after intubation, T0), 5 and 30 min after bypass start (T1 and T2), and 4 and $24 \mathrm{~h}$ after the end of bypass ( $\mathrm{T} 3$ and $\mathrm{T} 4$ ). The $25^{\text {th }}$ and $75^{\text {th }}$ percentiles are represented by a bar centered about the median; ranges are depicted by the error bars. ${ }^{*} P<0.05$ compared to baseline (Friedman test followed by Dunnett's test)
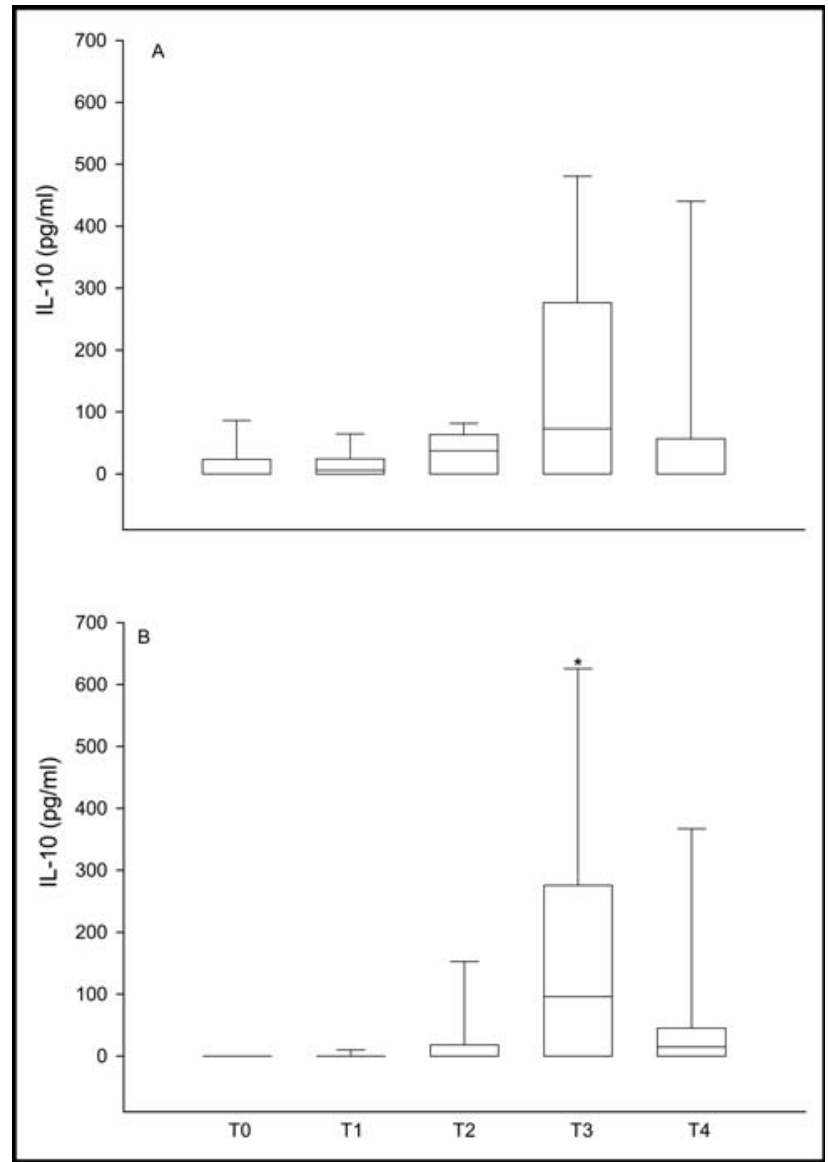

FIGURE 3 - Plasma IL-10 concentrations during and after bypass. Patients were submitted to bypass under normothermia with blood cardioplegia $(n=10$, panel A) or hypothermia with crystalloid cardioplegia ( $\mathrm{n}=10$, panel B). Time points for the assay were: baseline (after intubation, T0), 5 and $30 \mathrm{~min}$ after bypass start (T1 and T2), and 4 and $24 \mathrm{~h}$ after the end of bypass ( $\mathrm{T} 3$ and $\mathrm{T} 4$ ). The $25^{\text {th }}$ and $75^{\text {th }}$ percentiles are represented by a bar centered about the median; ranges are depicted by the error bars. ${ }^{*} P<0.05$ compared to baseline (Friedman test followed by Dunnett's test) 


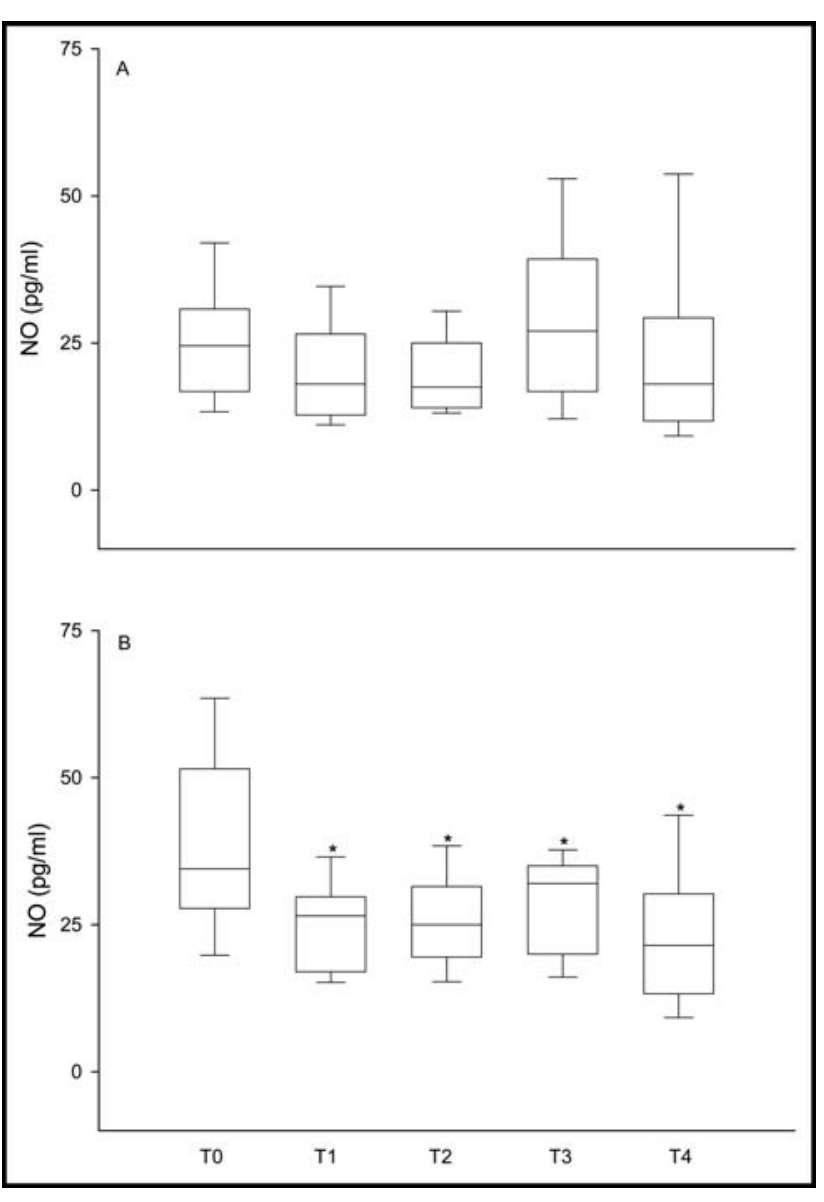

FIGURE 4 - Plasma nitrite plus nitrate concentrations during and after bypass. Patients were submitted to bypass under normothermia with blood cardioplegia ( $\mathrm{n}=10$, panel A) or hypothermia with crystalloid cardioplegia $(n=10$, panel B). Time points for the assay were: baseline (after intubation, T0), 5 and 30 min after bypass start (T1 and T2), and 4 and $24 \mathrm{~h}$ after the end of bypass (T3 and T4). The $25^{\text {th }}$ and $75^{\text {th }}$ percentiles are represented by a bar centered about the median; ranges are depicted by the error bars. ${ }^{*} P<0.05$ compared to baseline (Friedman test followed by Dunnett's test)

\section{Discussion}

This study investigated the effect of two conditions during CPB, namely perfusion temperature and cardioplegia type, on the systemic production of cytokines and NO. Patients undergoing CPB under either of these conditions showed elevated levels of each cytokine studied, however the time course of these increases differed. Cytokine levels were elevated earlier and longer in patients with hypothermic bypass with crystalloid cardioplegia. Furthermore, NO production was reduced under these latter conditions. Thus, perfusion temperature and cardioplegia type significantly affected the systemic inflammatory response. Our results show that cardiac surgery with CPB increased the systemic production of cytokines and that pro- and antiinflammatory systems can be activated simultaneously. These results reinforce previous reports ${ }^{2,3}$. We also showed that peak levels of all cytokines occurred $4 \mathrm{~h}$ after the end of bypass, again concordant with other studies $^{3,5,6}$. It is important to note that the groups in our study presented similar general characteristics, intraoperative parameters, and mortality rates. Increased systemic levels of IL-6 and IL-8 in CPB patients have been associated with myocardial reperfusion injury ${ }^{2}$ and inferior clinical outcome in adults ${ }^{11}$. They have also been correlated with impaired cardiovascular and respiratory function in children ${ }^{12}$. Moreover, transcardiac IL-6 and IL-8 are negatively correlated to cardiac index suggesting that reducing cardiac inflammatory reaction improves post-ischemic cardiac function ${ }^{13}$. Importantly we found that systemic production of pro-inflammatory cytokines increased regardless of the perfusion temperature or cardioplegia type, but the time course of these elevations differed between groups. Patients with hypothermic perfusion and crystalloid cardioplegia had elevated plasma concentrations of IL-6 and IL-8 that were detected earlier and persisted longer, up to $24 \mathrm{~h}$ after $\mathrm{CPB}$, than those with normothermic perfusion and with blood cardioplegia. In the former patients, peak levels of IL-6 correlated with IL-8 suggesting that, in addition to a temporal association, production of one cytokine could have triggered manufacture of the other to mediate the systemic inflammatory response. IL-10 production was only significantly increased in patients with hypothermic perfusion and crystalloid cardioplegia. This increase most likely indicates a counter-regulatory mechanism for the intense pro-inflammatory response observed in these patients. The effect of perfusion temperature and cardioplegia type during bypass on the development of SIRS has been investigated previously, but results are unclear. Some reports did not find differences in serum cytokine levels between patients with normothermic and hypothermic bypass ${ }^{5,14}$, while others found a more rapid decline in IL-8 plasma levels in the former ${ }^{6}$. The use of blood cardioplegia, compared to crystalloid cardioplegia, has been mainly associated with increased myocardial protection. In the former, reduced IL-6 levels were observed during and after bypass with superior cardiac index ${ }^{9}$ and lower expression of TGF-b associated with decreased endothelial damage ${ }^{10}$. Although increased levels of inflammatory cytokines were observed, which could induce iNOS activity, the systemic production of NO was reduced in HC patients compared to baseline. These results seem to be contradictory, however, increased concentrations of IL-10, which inhibits iNOS, could have been responsible, at least in part, for the reduced levels of NO. Reduced NO production during bypass has been reported previously. In patients submitted to CPB under 
hypothermia, respiratory changes indicative of pulmonary dysfunction coincided with decreased exhaled $\mathrm{NO}^{15}$. Another study in patients that received bypass with different degrees of hypothermia showed reduced plasma NO levels until the first post-operative day followed by recovery ${ }^{16}$. This result is in accord with our findings in that reduced NO concentrations were found in HC patients until $24 \mathrm{~h}$ after the end of CPB. Treatment of patients with inhaled NO at low concentrations during and after bypass ${ }^{17}$, or with NO donor during reperfusion ${ }^{13}$, reduced myocardial injury ${ }^{17}$ and the cardiac inflammatory reaction, as assessed by IL-6, IL-8 and TNF-a levels ${ }^{13}$. In line with this report, our study showed an association between systemically reduced NO production and increased duration of elevated cytokine levels in patients with hypothermia and crystalloid cardioplegia, although no significant differences were detected in clinical outcome between these patients and those with normothermia and blood cardioplegia. Blood cardioplegic solution supplemented with L-arginine, the substrate for NO synthesis, was associated with reduced release of biochemical markers of myocardial damage, suggesting improved myocardial protection $^{18}$. A limitation of the present study is the small number of patients. These low numbers do not allow an accurate assessment of clinical outcome. Also, the study design precludes evaluation of the individual role of perfusion temperature or cardioplegia type. In addition, considering that the definition of hypothermia and normothermia has been heterogeneous between authors ${ }^{14}$, and that additives in cardioplegic solutions would provide added protection, this could hinder an accurate comparison of results between various groups.

\section{Conclusions}

These results describe an association between reduced systemic production of NO and increased IL-6, IL-8 and IL-10 levels in CPB patients with hypothermia and crystalloid cardioplegia. Our findings suggest that the temperature perfusion and/or cardioplegia type are determining factors for the intensity of the systemic inflammatory response. Further studies with a larger patient population are needed to determine whether these factors affect the clinical outcome.

\section{References}

1. Levy JH, Tanaka KA. Inflammatory response to cardiopulmonary bypass. Ann Thorac Surg. 2003;75:715-20.

2. Kawamura T, Nara N, Kadosaki M, Inada K, Endo S. Prostaglandin $\mathrm{E}_{1}$ reduces myocardial reperfusion injury by inhibiting proinflammatory cytokines production during cardiac surgery. Crit Care Med.
2000;28:2201-8.

3. Volk T, Schmutzler M, Engelhardt L, Docke WD, Volk HD, Konertz W, Kox WJ. Influence of aminosteroid and glucocorticoid treatment on inflammation and immune function during cardiopulmonary bypass. Crit Care Med. 2001;29:2137-42.

4. Wang WZ, Anderson G, Fleming JT, Petter FW, Franken RJ, Barker J, Acland RD. Lack of nitric oxide contributes to vasospasm during ischemia/ reperfusion injury. Plast Reconstr Surg. 1997;99:1099-1108.

5. Honore PM, Jacquet LM, Beale RJ. Renauld JC, Valadi D, Noirhomme P, Goenen M. Effects of normothermia versus hypothermia on extravascular lung water and serum cytokines during cardiopulmonary bypass: a randomized, controlled trial. Crit Care Med. 2001;29:1903-9.

6. Birdi I, Caputo M, Underwood M, Bryan AJ, Angelini GD. The effects of cardiopulmonary bypass temperature on inflammatory response following cardiopulmonary bypass. Eur J Cardiothorac Surg. 1999;16:540-5.

7. Xiao H, Remick DG. Correction of perioperative hypothermia decreases experimental sepsis mortality by modulating the inflammatory response. Crit Care Med. 2005;33:161-7.

8. Qing M, Vasquez-Jimenez JF, Klosterhalfen B, Sigler M, Schumacher K, Duchateau J, Messmer BJ, von Bernuth G, Seghave MC. Influence of temperature during cardiopulmonary bypass on leukocyte activation, cytokine balance, and post-operative organ damage. Shock. 2001;15:372-7.

9. Liebold A, Langhammer T, Brunger F, Birnbaum DE. Cardiac interleukin-6 release and myocardial recovery after aortic crossclamping: crystalloid versus blood cardioplegia. J Cardiovasc Surg. 1999;40:633-6.

10. Billia F, Carter K, Rao V, Gorczynski R, Feindel C, Ross HJ. Transforming growth factor-beta expression is significantly lower in hearts preserved with blood/ insulin versus crystalloid cardioplegia. J Heart Lung Transplant. 2002;21:918-22.

11. El Azab SR, Rosseel PMJ, de Lange JJ, Groeneveld $A B$, van Strik R, van Wisk EM, Scheffer GJ. Dexamethasone decreases the pro- to antiinflammatory cytokine ratio during cardiac surgery. Br J Anaesth. 2002;88:496-501.

12. Gessler P, Pfenninger J, Pfammatter JP, Carrel T, Baenziger $\mathrm{O}$, Dahinden C. Plasma levels of interleukin-8 and expression of interleukin-8 receptors on circulating neutrophils and monocytes after cardiopulmonary bypass in children. J Thorac Cardiovasc Surg. 2003;126:718-25. 
13. Freyholdt T, Massoudy $\mathrm{P}$, Zahler S, Henze R, Barankay A, Becker BF, Meisner H. Beneficial effect of sodium nitroprusside after coronary artery bypass surgery: pump function correlates inversely with cardiac release of proinflamamtory cytokines. J Cardiovasc Pharmacol. 2003;42:372-8.

14. Beghetti M, Silkoff PE, Cavamori M, Holtby HM, Slutsky AS, Adatia I. Decreased exhaled nitric oxide may be a marker of cardiopulmonary bypass-induced injury. Ann Thorac Surg. 1998;66:532-4.

15. Yamada S. Impaired endothelial responses in patients with deep hypothermic cardiopulmonary bypass. Kurume Med J. 2004;51:1-7.

16. Gianetti J, Del Sarto P, Bevilacqua S, Vassalle C, De Filippis R, Kacila M, Farneti PA, Clerico A, Glauber M, Biagini A. Supplemental nitric oxide and its effect on myocardial injury and function in patients undergoing cardiac surgery with extracorporeal circulation. J. Thorac Cardiovasc Surg. 2004;127:44-50.

17. Gaudino M, Zamparelli R, Andreotti F, Burzotta F, Iacoviello L, Glieca F, Benedett M, Maseri A, Schiavello R, Possati G. Normothermia does not improve postoperative hemostasis nor does it reduce inflammatory activation in patients undergoing primary isolated coronary artery bypass. J. Thorac Cardiovasc Surg. 2002;123:1092-1100.

18. Carrier M, Pellerin M, Perrault LP, Bouchard D, Page P, Searle N, Lavoie J. Cardioplegic arrest with Larginine improves myocardial protection: results of a prospective randomized clinical trial. Ann Thorac Surg. 2002;73:837-41.

\section{Correspondence:}

Profa. Beatriz Martins Tavares Murta

Departamento de Ciências Biológicas (UFTM)

Praça Manoel Terra, 330

38015-050 Uberaba - MG Brazil

Phone: (55 34)3318-5467 / 5488

Fax: (55 34)3318-5462

bmurtafarmaco@dcb.uftm.edu.br
Conflict of interest: none Financial source: $\mathrm{CNPq}$

(Process 304455/2003-2)

Received: March 16, 2007

Review: May 14, 2007

Accepted: June 15, 2007

\section{How to cite this article}

Tavares-Murta BM, Cordeiro AO, Murta EFC, Cunha FQ, Bisinotto FM. Effect of myocardial protection and perfusion temperature on production of cytokines and nitric oxide during cardiopulmonary bypass. Acta Cir Bras. [serial on the Internet] 2007 July-Aug;22(4). Available from URL: http://www.scielo.br/acb 